\title{
Pre-service Teachers' Beliefs About Inclusive Education Before and After Multi-Compared to Mono-professional Co-teaching: An Exploratory Study
}

\author{
Roswitha Ritter ${ }^{1 *}$, Antje Wehner ${ }^{1,2}$, Gertrud Lohaus ${ }^{1}$ and Philipp Krämer ${ }^{2}$ \\ ${ }^{1}$ Molecular Plant Research, Biology, School of Mathematics and Natural Sciences, University of Wuppertal, Wuppertal, \\ Germany, ${ }^{2}$ School of Education, Institute of Educational Research, University of Wuppertal, Wuppertal, Germany
}

Teacher beliefs are action guiding in the classrooms. Teacher beliefs about inclusive education are thus a crucial pre-requisite for its success. Therefore, those beliefs have to be addressed during the first phase of teacher training. Generally accepted concepts or operationalized definitions would be valuable guidelines for pre-service teachers and their educators. However, neither the ones nor the others are available at present.

OPEN ACCESS

Edited by:

Teresa Leavitt,

Brigham Young University,

United States

Reviewed by:

Joseph Samuel Backman, Alpine School District, United States Jessica Erin Charles, Bank Street College of Education, United States

*Correspondence: Roswitha Ritter rritter@uni-wuppertal.de

Specialty section:

This article was submitted to

Teacher Education,

a section of the journal

Frontiers in Education

Received: 18 March 2019 Accepted: 03 September 2019 Published: 18 September 2019

Citation:

Ritter R, Wehner A, Lohaus G and Krämer P (2019) Pre-service Teachers' Beliefs About Inclusive Education Before and After Multi-Compared to Mono-professional Co-teaching: An Exploratory Study. Front. Educ. 4:101 doi: 10.3389/feduc.2019.00101
Therefore, pre-service teachers have to fall back on their own beliefs, a rather unexplored notion so far. Within the present study, pre-service teachers' beliefs about inclusive education were assessed before and after an academic seminar. During this academic seminar, participants co-taught in either multi-professional (i.e., one pre-service teacher for special educational needs and one for general education) or mono-professional (i.e., both pre-service teachers for special educational needs or both for general education) teams in inclusive classes of secondary schools. Pre-service teachers' beliefs were assessed with the help of concept-maps, which were created by the participants at two testing times. The concept-maps were analyzed employing graph-theoretical approaches as well as qualitative, summarizing content analysis methods. Results show that pre-service teachers who worked in multi-professional teams expanded their conceptualization of inclusive education to include facets like individualization and differentiation, while pre-service teachers who worked in mono-professional teams displayed no such expansion. Also, the conceptualization of pre-service teachers who worked in mono-professional teams contained a larger percentage of propositions addressing disadvantages and negative consequences of inclusive education. Therefore, it is concluded that multi-professional co-teaching during teacher training helps prepare teachers for successful inclusive education.

Keywords: beliefs about inclusion, co-teaching, pre-service teachers, teacher training, concept maps

\section{INTRODUCTION}

The United Nations Convention on the Rights of Persons with Disabilities states that children must not be excluded from the general education system on the basis of disability (United Nations, 2006, p. 17). The Convention orders that "State Parties shall ensure an inclusive education system at all levels [...]" (United Nations, 2006, p. 16). In Germany, the UN-Convention was ratified in 2007 
and incepted in 2009. Since then, parents of children with special needs have the right to choose either mainstream or special needs schools. Consequently, there has to be inclusive education in mainstream schools. For it to be successful, teachers' beliefs are a crucial factor.

Therefore, it is essential that pre-service teachers' beliefs be addressed during teacher training, and an operationalized definition or generally accepted concept of inclusive education could serve as a guideline for that. However, there is no such commonly agreed upon operationalized definition or concept of it. Therefore, pre-service teachers have to fall back onto their own beliefs about inclusive education, a notion that is rather undiscovered.

Many scholarly works emphasize that co-teaching is a crucial pre-requisite for successful inclusive education. Co-teaching in multi-professional teams at the pre-service level entails that the team partners have to reflect on and discuss about their beliefs when negotiating different teaching strategies. Exactly that may lead to a transformation of individual beliefs to facilitate successful inclusive education, and thus may serve as an appropriate means to address pre-service teachers' beliefs.

In the international research context, teacher beliefs are defined as being a psychological concept describing a person's views and propositions about the world which are accepted as being true. Hereby, it is the person's individual decision to create criteria for the relevance and importance of these views and propositions; they don't have to follow logical orders. For the individual person, however, they are informative and action guiding (Kagan, 1992; Richardson, 1996; Richarson and Placier, 2002).

Beliefs can be clearly separated from the theoretical notion of knowledge, as they do not have to comply with any criteria of truth (Richardson, 1996). Moreover, beliefs are dealt with as being action guiding in educational processes, particularly in poorly defined and complex situations, because they help simplify situations and identify aims and objectives (Nespor, 1987). As this work is concerned with teaching and teacher action, beliefs are also understood to refer to both beliefs about the ability to teach and design learning processes as well as beliefs about generating and organizing knowledge (i.e., epistemological beliefs).

Beliefs are of particular importance for teachers as they constitute the grounds for professional everyday actions, whichin the case of teachers-many a time consist of influencing other people in interpersonal relationships (Mandl and Huber, 1983). Teachers tend to create hypotheses about the learning processes of their pupils and the necessary (individual) support on the basis of their beliefs. In other words, beliefs constitute the expert knowledge on the ground of which teachers draw decisions concerning teaching and interaction (Biesta et al., 2015).

Gale et al. (2017) drew on Bourdieu and Passeron's (1990) concept of "pedagogic work" to identify three principles as an indicator of inclusive pedagogy: (a) a belief that all students are of value for the learning environment, (b) a design that values differences, and (c) actions that work with rather than act on students. This means that there has to be an interaction of these three principles, with beliefs being the ideas or principles that "name and frame good teaching." Beliefs about teaching inform pedagogic design and action (Bourdieu and Passeron's (1990), p. 349). It is particularly the belief about inclusive teaching that informs teachers' actions with respect to valuing heterogeneity, designing adequate learning environments, and taking appropriate measures. As a consequence, these beliefs have to be addressed within teacher training to prepare future teachers to be able to deliver successful inclusive teaching. In order to do so, an operationalized definition or a generally accepted concept of inclusive education could be a valuable guideline.

However, despite the UN demand for State Parties to ensure an inclusive education system, there is neither a generally accepted concept nor an operationalized definition of the term inclusive education (cf.: Farell, 2004; Göransson and Nilholm, 2014). So far, there have been several first attempts to provide common bases for the conceptualization of the term. Artiles et al. (2006), for instance, state that inclusive education is an ambitious and far-reaching notion with multiple meaning ranging from physical integration in general education classrooms to transformation of school-buildings and reconfiguration of educational systems.

In line with that, Göransson and Nilholm (2014) provided four different types of definition:

(1) The placement definition, denoting that inclusive education is achieved by the mere placement of pupils with and without special educational needs in mainstream classrooms

(2) The specified individualized definition, which identifies inclusion as meeting the social and academic needs of pupils with disabilities

(3) The general individualized definition, regarding inclusion as meeting the social and academic needs of all pupils in the classroom

(4) The community definition, which expects educational inclusion to create social communities and companionships.

However, Artiles as well as Göransson and Nilholm agree that there is no operationalized definition or generally accepted concept. This is supported by Nilhom and Göransson (2017), who concluded from their analysis of journal articles that there is a lack of clarity concerning the definition of inclusion. This is the more troublesome as the concept is being used to define research and practice. Particularly teacher trainers and future practitioners in inclusive settings need guidelines as to what inclusive education is and how it can be implemented. As a consequence, instead of relying on a clear definition of inclusion they have to rely on beliefs about and the individual concepts of inclusive education (Grosche, 2015).

So far, little is known about pre-service teachers' beliefs about and individual concepts of inclusive education, important aspects of its definition, and communalities or differences between teachers' subjective conceptualization and definitions derived from experts' statements. Makoelle (2014) qualitatively analyzed six interviews with South-African teachers and deduced three themes which contribute to the explanation of different understandings of inclusive education. The first theme states that conceptualization of inclusive pedagogy appears not to be universal, but depends on the context. The second theme 
addresses two divergent discourses about inclusive education, namely a special needs discourse and a discourse of full inclusion; these two discourses influence the understanding of inclusion. Theme number three addresses the operationalizing of inclusive pedagogy, which ranges from strategy-oriented, and therefore teacher-centered, to creativity and flexible teaching, which is learner centered. These three themes provide first insights into teachers' conceptualization of inclusion and basically confirm the above-mentioned vagueness of the definition; they do not, however, operationalize the term inclusive education. Nor can they be generalized due to the small and specific sample group.

Przibilla et al. (2018) analyzed the answers of 182 in-serviceteachers to the task Define inclusive education in your own words as part of an online survey to investigate these teachers' beliefs about inclusive education. An inductive, summarizing, qualitative content analysis resulted in a system of 27 categories grouped in 9 dimensions, which address topics ranging from politics and educational system to attitude, participation, cooperation, differentiation as well as problems and barriers. This system of categories represents the aggregate belief of all teachers involved; it consists of a variety of possible facets, as exemplified by the topics of the dimensions. However, the authors emphasize that the results provide first insights into teachers' ideas and beliefs about inclusive education only, and they strongly recommend extended research on the conceptualization of inclusion. Hereby, it of particular importance to extend research on pre-service teachers' conceptualizations of inclusive education and the means and methods to address them during teacher training.

A possible approach to address pre-service teachers' beliefs may be to provide opportunities in which pre-service teachers of different courses of study collaborate in inclusive classrooms and reflect on and discuss about their beliefs. Scruggs et al. (2007) found that co-teaching leads to professionalizing of both participating team partners. The authors state that co-teachers benefitted from their collaboration as they reported to have learned from each other and adapted their teaching to the needs of their pupils. In other words, co-teachers enhanced their beliefs about self-efficacy and teaching abilities.

In the context of inclusive education, not only beliefs about the capability to teach groups of heterogeneous pupils, but also beliefs about pupils' knowledge and learning (i.e., epistemological belief), particularly beliefs in improvable learning abilities and effortful learning, are key factors. Silverman (2007) identified an urgent need to develop high-level (epistemological) beliefs during preservice teacher training, as there is evidence that new teachers are lacking in this area. Jordan et al. (2009), however, extracted from their literature review that it is challenging to transform teachers' beliefs; rather, their development is almost entirely left to the field experiences, a component beyond the control of teacher educators. Therefore, the authors conclude, it is essential for teacher educators to ensure that pre-service teachers have practicum experience in which there are opportunities to examine and foster their beliefs. This is also supported by the findings of Hopkins et al. (2018) who demonstrated in their study that, through elective-compulsory participation in supplementary fieldwork, pre-service teachers restructured their beliefs about pupils with learning difficulties as well as about their ability to teach them. To a great deal, this was found to be due to pre-service teachers having their preconceived ideas about people with intellectual disabilities challenged and to their seeing progress of their pupils. Exactly that-academic progress of the pupils-was also demonstrated for co-taught classes, where pupils with and without disabilities benefitted greatly from there being two teachers in the classroom (Scruggs et al., 2007).

Additionally, for beliefs to be changed it is essential that teachers make explicit their implicit beliefs (Bendixen and Rule, 2004). Howard et al. (2000) state that tacit beliefs can become explicit when teachers reflect on them and discuss them, and when they are challenged by feedback from colleagues and peers. Also, teachers need to acquire evidence of improvement in their pupils' outcomes in order to transform their beliefs (Guskey, 2002).

Consequently, co-teaching in the pre-service level not only includes practicum experience, it also facilitates transfer of expertise and extension of teaching skills, which leads to higher self-efficacy beliefs. Moreover, it leads to the acquisition of the experience that pupils improve academically, which leads to higher epistemological beliefs. Furthermore, co-teachers make explicit their implicit beliefs, reflect on them, may find them challenged through negotiation about teaching strategies, and also receive feedback on them from their partners and their mentors. Therefore, it is to be assumed that co-teaching in the pre-service level can influence and transform pre-service teachers' beliefs and thus contribute to preparing future teachers for successful inclusive education.

Adequate action in inclusive classrooms highly depends on teacher beliefs; therefore, they have to be addressed during teacher training. Generally accepted concepts or operationalized definitions of inclusive education could be valuable guidelines to address these beliefs; however, neither the one nor the other are available. Therefore, pre-service teachers have to fall back on their own beliefs. So far, there is scarce knowledge about the composition of pre-service teachers' beliefs about inclusive education as well as their influencing factors. Therefore, the first research question within this study is:

- What are pre-service teachers' beliefs about inclusive education before as well as after a period of practical experience?

Co-teaching is one of the pre-requisites for successful inclusive education. There is evidence to suggest that it triggers reflection and therefore transformation of teachers' beliefs. Thus, the second research question is:

- Is there a difference between the beliefs of teacher trainees working in mono- and those working in multi-professional co-teaching teams after the practical experience?

\section{MATERIALS AND METHODS}

\section{Academic Course}

Basis for the investigation is an elective-compulsory academic course offered for teacher trainees for Special Educational Needs 
(henceforth referred to as SEN) and those for General Education (henceforth referred to as GE) within the teacher education program at the University of Wuppertal, Germany. The course consists of three episodes: an introductory theoretical one (A), one of practical experience in inclusive classes in secondary schools (B), and one of reflection (C). In the following, the contents of the individual episodes are explained in detail:

(A) During the theoretical episode, teacher trainees are introduced to topics concerning inclusive education, such as the theoretical background of co-teaching, educational methodologies and strategies for inclusive settings, or instructional techniques (e.g., direct instruction, peertutoring, etc.) and aids for different special educational needs. Teacher trainees were then matched into tandems to form either mono-professional (two teacher trainees of GE or two teacher trainees of SEN) or multi-professional (one teacher trainee of GE and one teacher trainee of SEN) teams after the partners had had the opportunity to extensively introduce themselves to each other (e.g., by transferring expertise via jigsaw-activities, by sharing personal strengths and weaknesses as well expectations of each other).

(B) During the practical episode, these tandems spent one complete school morning per week in inclusive classes at local schools for a period of 12 consecutive weeks. After having familiarized with the pupils and teachers in the class, they planned and conducted lessons on their own responsibility, but under the guidance of the subject teacher and the teacher for SEN at the schools. Lessons were given in one of the studied subjects of the two teacher trainees in the tandem; they were planned and conducted collaboratively, meaning that both partners' expertise was needed to provide access to the subject content for all pupils in the class.

(C) At the end of the practical phase there was an episode of reflection, in which experiences were discussed on a metalevel with the instructors at the university, the intention of this episode being to facilitate a reflection of beliefs about inclusive education and pupils with exceptional needs (for a detailed description see Ritter et al., 2018).

\section{Participants}

The elective-compulsory academic course for teacher trainees of GE and for SEN was first offered in the summer term 2016 (April to September) and following that in four subsequent terms, i.e., five consecutive terms until summer term 2018. Within that time, a total of 97 teacher trainees attended the seminar, 53 of which were teacher trainees of SEN and 44 were teacher trainees of GE; 63 teacher trainees formed a total of 32 multi-professional teams (one teacher trainee of GE was in a team with an inservice teacher for SEN), 34 teacher trainees formed a total of 17 mono-professional teams. Eighty participants were female. On average, the participants were 22.9 years old, with a standard deviation of 3.2 years. The teacher trainees of SEN were in their Bachelor's program in their second or third semester, the teacher trainees of GE were in their Master's program (semester 2, 3, or 4). Eighty one percentage of all participants reported to have had practical experience in schools already; $66 \%$ reported to have had experience with pupils with SEN in schools and $56 \%$ reported to have had experience with children with SEN in private contexts. About half of the participants reported to have attended seminars on inclusion prior to attending this electivecompulsory seminar, $40 \%$ reported to have attended seminars on the topic of co-teaching.

\section{Data Collection and Analysis}

The participating teacher trainees $(N=97)$ created concept maps before (t1) and after ( $\mathrm{t} 2)$ the elective-compulsory seminar. Concept maps were originally invented to structure and visualize children's responses in clinical interviews (Novak and Cañas, 2008), and later advanced to a general technique for learning, teaching, and assessing structural knowledge (Novak and Cañas, 2010). They consist of labeled entities that represent concepts; the concepts are connected by directed arrows which carry a predicate to form propositions of two linked concepts and their linking-word. These propositions are fundamental units of meaning stored in our cognitive structure (Novak and Cañas, 2010).

The structure of the concept-map represents the structure and composition of knowledge of a person. In order to analyze concept maps using algorithmic methods, they have to be modeled as mathematical graphs. Each graph consists of nodes (concepts) and edges (links), which allows for the usage of graph-theoretical techniques for analysis. There are additional techniques to not only analyze individual concept maps, but also concept maps of whole groups of test persons together. Mühling (2017) summarizes different appropriate techniques to define the procedure of Concept Landscaping, which combines all concept maps of a group of people with all the contained nodes and edges to one common graph. This common graph can then be analyzed using statistical or graph-theoretical techniques, one of them being the technique of pathfinder-analysis (Mühling, 2014). Pathfinder networks only contain links made by very many participants. Very many in this context means that for the chosen parameters, the total amount of the used links is maximal (parameters $p=$ total number of concepts -1 ; $\mathrm{q}=$ infinite); there is no other possibility to connect all concepts and achieve a higher number of links. The lengths and paths of pathfinder networks contain information about how similar the connected concepts are in the original data. Thus, the pathfinder network is an algorithmic method of edge-pruning a graph by keeping all nodes and systematically remove edges (Mühling, 2017).

This strategy determines the most important structural characteristics of a group of concept maps, thus generating a network consisting of the most frequently used nodes and edges. The less frequently used nodes and edges, however, are not merely eliminated. Instead, there are different parameters to govern the algorithm to render networks that are representative of all conflated concept maps (Mühling, 2014).

The resulting pathfinder networks can then be analyzed according to their structure. Kinchin et al. (2000) determined three different organization types of concept maps: (1) the chain structure, the simplest connection of one concept with the respective next, shows a linear connection of several concepts; (2) the spoke structure, slightly more elaborate, shows 
a central concept connected with several others; (3) the netstructure, where all the concepts are interconnected several times. The chain structure represents linear knowledge, without interconnection, the spoke-structure is a representation of slightly more elaborate and interconnected knowledge, and the net-structure represents a whole set of puzzle-pieces belonging to a knowledge domain. These puzzle-pieces are interconnected and mutually essential to make for the whole. Furthermore, statistical measures such as betweenness centrality, degrees, or communalities can be applied to capture the characteristics of the landscape-graph. Analyses were carried out using the package comato for the statistical program $R$.

When creating these concept maps, teacher trainees were entirely free to choose any concept or linking word that they considered important to elicit on the guiding question What is inclusive education? There was neither a limit to the concepts nor to the linkings; linking-arrows could be uni- or bidirectional. In order to be able to conflate the individual concept maps to create landscape graphs, the original concepts used by the participants in their concept-maps had to be standardized prior to analysis. For that purpose, a summarizing content analysis of all the used concepts was performed, resulting in a set of 34 concepts.

In addition to the analysis of the structure and composition of the participants' knowledge, the propositions, i.e., two concepts and their linking predicate as the smallest units of analysis of the concept maps, were analyzed in order to gain insight into the semantic context of the concepts. For this purpose, an inductive, summarizing qualitative content analysis (cf.: Mayring, 2015) was performed. Approximately half of all 2,049 propositions were used to create a system of categories (for a detailed description see Ritter et al., 2019), which then built the basis to code all the propositions using the software MAXQDA. Thereupon followed statistical analyses of the number of codings in given categories at the different testing times and also for participants in different team-constellation (multi- or mono-professional teams) using Excel and SPSS. Thus, comparisons can be drawn between the different testing times as well as between the maps originating from teacher trainees in multi- with those in mono-professional teams at testing time $\mathrm{t} 2$. Thereby it can be explored (1) which concepts of inclusive education exist among teacher trainees and (2) whether there is a change of these concepts during the course of the seminar and also (3) whether there is a difference between teacher trainees in multi- and those in mono-professional teams.

\section{RESULTS}

\section{Graph-Theoretical Analysis}

As a first step, all 97 concept maps of testing time t1 (before the seminar) and testing time $\mathrm{t} 2$ (after the practical episode) were standardized, transferred into mathematical graphs and amalgamated to render landscape-graphs. Of these graphs, pathfinder networks were created to visualize any differences before and after the seminar.

Furthermore, pathfinder networks were created from the concept-maps originating from participants in mono- and those in multi-professional teams at $\mathrm{t} 2$ to depict shared or different knowledge of a given group of participants.
The pathfinder network of all participants at testing time $\mathrm{t} 1$ shows the common belief about inclusive education before the seminar (see Figure 1).

As the visual impression conveys, the concept Inclusive Education is the most central one. This can be supported by calculating the degree, a measure that shows how many connections a given node has. Concepts that are very central in the network receive a high degree measure, marginal concepts receive low numbers. For the concept Inclusive Education, the degree measure is 19, followed - with a big difference - by the concepts Teacher for SEN (9), Pupils with SEN (8), and Teacher for GE (7). Among the least central nodes with a degree measure of 1 each are Heterogeneity, Individualizing, Support, and Equality.

After the seminar, at testing time $\mathrm{t} 2$, the pathfinder network again visualizes that the concept Inclusive Education is the most central one, meaning that this node has the highest number of connections (Figure 2). Again, this is supported by the degree measure, which renders a value of 22 , followed by the concept Teacher for SEN (13), Teacher for GE (12), and Pupils with SEN, Teachers, Pupils and Collaboration/Team (8 each). The least central concepts with a degree of 1 are Challenge, Heterogeneity, Resources, and Lessons/Planning.

To determine whether there is a difference in the conception of inclusive education at testing time $\mathrm{t} 2$ between participants in multi- and those in mono-professional teams, pathfinder networks were created for each group. The pathfinder network created from the concept maps of participants in multiprofessional teams (Figure 3) shows that the concept Inclusive Education is connected with every other concept in the network. This is also supported by the degree measure: For Inclusive Education, the calculated degree is 19 (total number of concepts-1), followed - again with a big difference - by the concepts Pupils with SEN, All Pupils, and Teacher for SEN (degree measure of 8 each).

As for the pathfinder network created from the concept maps of participants in mono-professional teams (Figure 4), the concept Inclusive Education is the one with the most connections; it is, however not connected with every other concept in the network (10 connections within 12 concepts). Concerning the number of connections, the concept Teacher for SEN is ranked 2 (8 connections within 12 concepts), followed by Teacher for GE (7 connections within 12 concepts). The least connected concepts are Resources and Parents (1 connection each).

It is also important to note that the pathfinder network from participants in multi-professional teams contains 20 nodes, whereas the network from participants in mono-professional teams only contains 12 nodes. This is also represented by the measure diameter, which expresses the longest shortest path between any two nodes. For the pathfinder network of participants in multi-professional teams, the measure is 236 , for the one of participants in mono-professional teams, it is 194 . Among the concepts in the pathfinder network of participants in multi-professional teams are the concepts Inclusion and Integration, Differentiation, Methods, or Equality; these concepts are totally absent in the pathfinder network of participants in mono-professional teams. Moreover, in the pathfinder network 


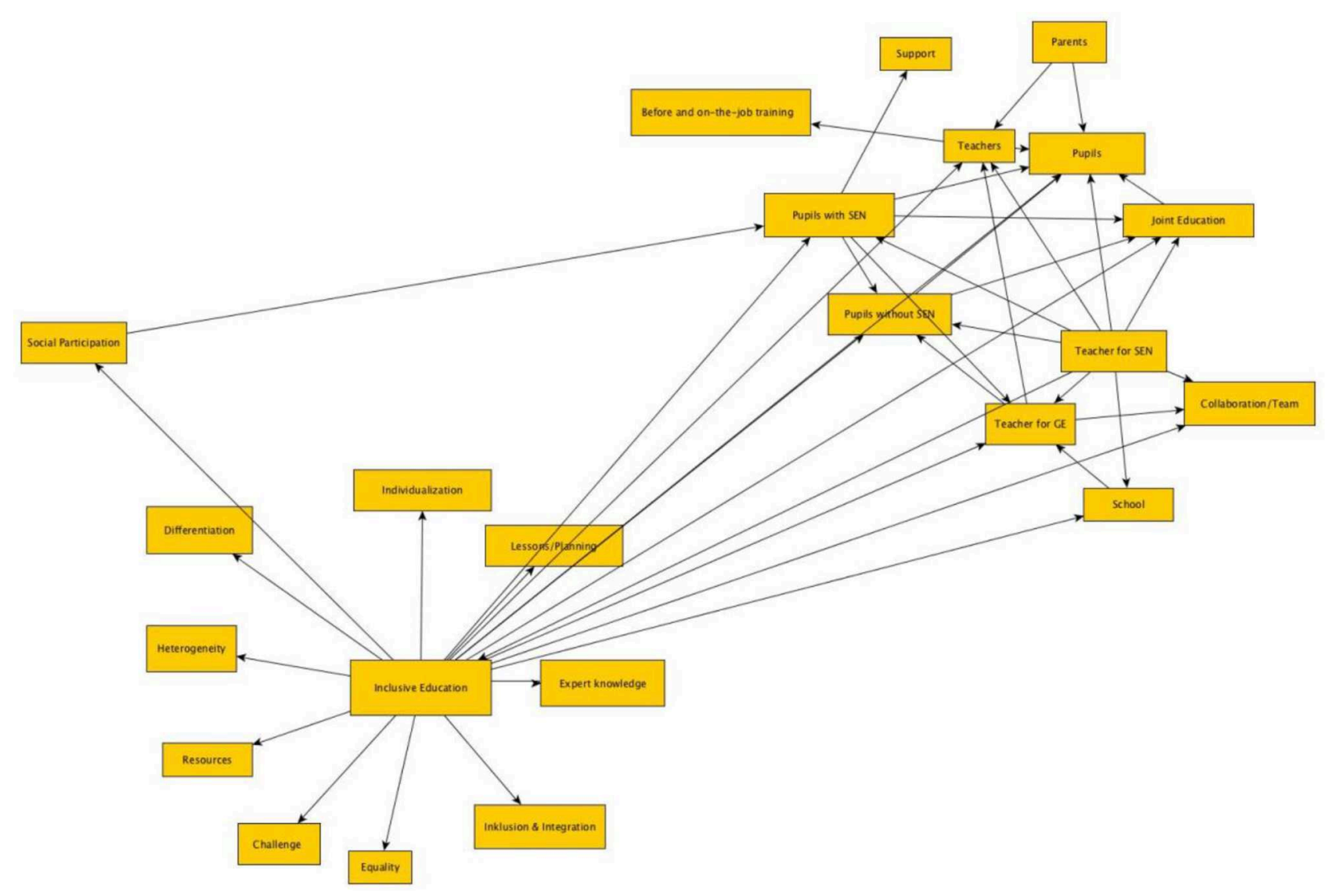

FIGURE 1 | Pathfinder network of all teacher trainees at t1 $(N=97)$.

created from the concept-maps of participants in monoprofessional teams only concepts addressing school, teachers and pupils are densely interconnected, the others are in a spoke structure solely connected to the concept Inclusive Education.

\section{Content Analysis}

Before being able to analyze the obtained propositions from the concept maps, a system of categories had to be compiled by performing an inductive, summarizing qualitative content analysis (Mayring, 2008, 2015) from approximately half of the data material. For this purpose, the propositions were paraphrased, generalized, selected and reduced to result in a final system of 35 categories grouped in 7 dimensions (for a detailed description see Ritter et al., 2019). An excerpt of the system of categories is displayed in Table $\mathbf{1}$.

This system of categories was then used to code the complete data material (2,049 propositions) of the concept maps. On average, a teacher trainee's subjective concept of inclusive education consisted of 10 propositions. Therefore, the 10 categories into which the most propositions were coded were determined for the testing times $\mathrm{t} 1$ and $\mathrm{t} 2$ for all participants to investigate whether there is a change of beliefs about inclusive education after having attended the seminar. For $\mathrm{t} 2$, these 10 categories were then established for multi- and for monoprofessional team members separately to investigate whether there is a difference of belief-change depending on the respective team partner (Table 2; for reasons of economic use of space, only the numbers of the categories are given in this and all subsequent tables. To find the corresponding categories, please refer to Table $\mathbf{1}$ ).

For t1, roughly half of all propositions (47.9\%) were coded into the categories of dimensions 3 SCHOOL-LIFE AND TEACHING and 4 COLLABORATION AND PROFESSIONAL ROLES, which shows that teacher trainees' beliefs about inclusive education concentrate on the aspects of schooling and teaching. Categories of these two dimensions are on rank 1 to rank 5 of the ones containing the most codings. Additionally, about $10 \%$ of the propositions were coded into categories of dimension 6 PREREQUISITES AND BARRIERS, about $7 \%$ of the propositions were coded into categories of dimension 1 VALUES AND ATTITUDES.

For $\mathrm{t} 2$, there are also categories among the top 10 that stem from the dimensions 6 PREREQUISITES AND BARRIERS and 7 Disadvantages AND CONSEQuences, a fact that discloses a shift of the beliefs to the problems and barriers of inclusive education. Also, the category 3.4 Inclusive education denotes good teaching, successful individualization and adapted 


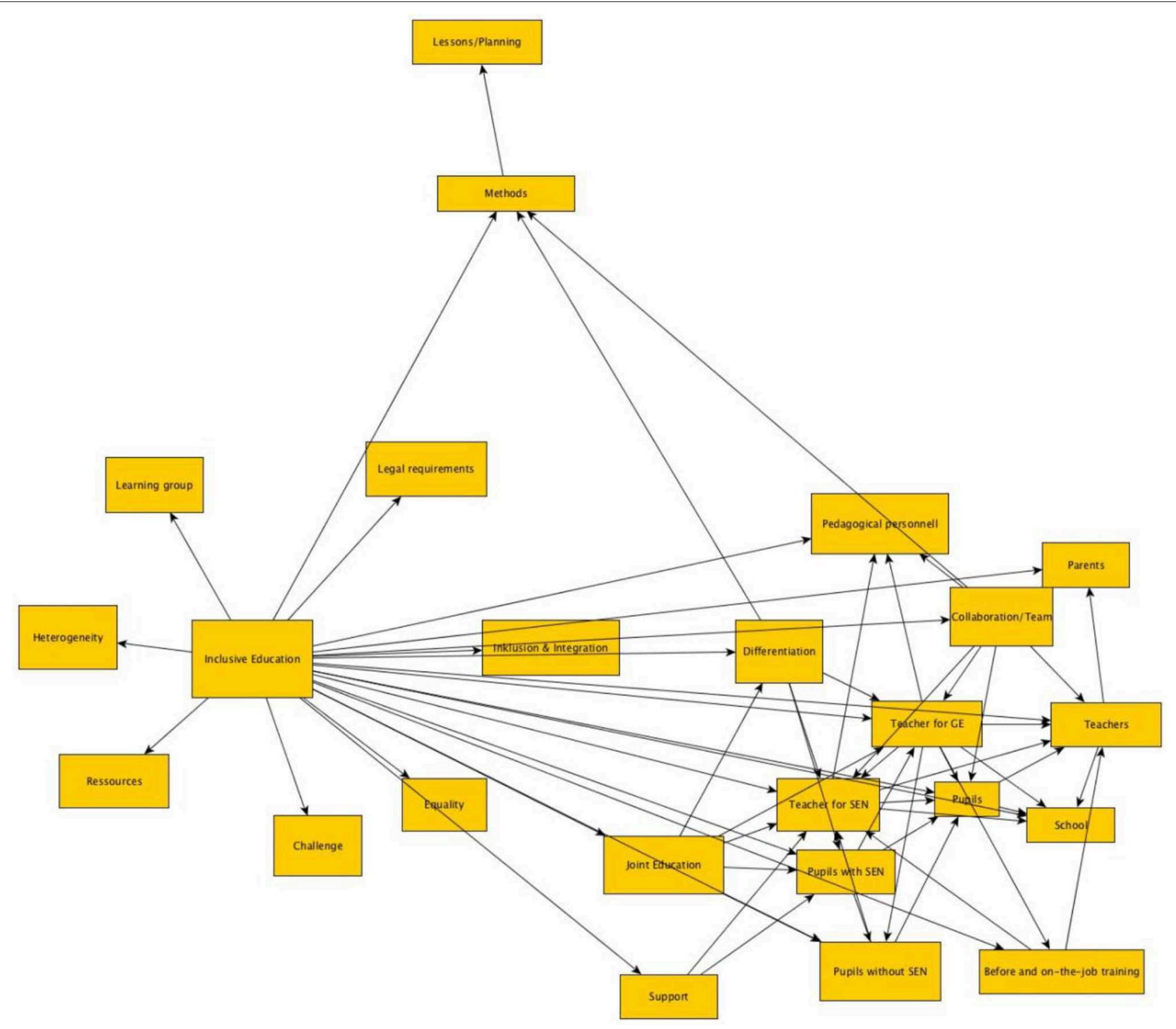

FIGURE 2 | Pathfinder network of all teacher trainees at t2 $(N=97)$.

differentiation (e.g., through materials, methods, concepts, coteaching) contains significantly more codings at $\mathrm{t} 2$ than at $\mathrm{t} 1$. Moreover, the categories of dimension 3 School-life and teaching and dimension 4 COLLABORATION AND PROFESSIONAL ROLES contain more than half of all propositions at $\mathrm{t} 2$; the proportion of propositions in dimension 6 PREREQUISITES AND BARRIERS and 7 DISADVANTAGES AND CONSEQUENCES increased to about $1 / 5$ of all propositions. No category of dimension 1 Values and attitudes is among the 10 most frequently mentioned ones.

To compare the different testing times and teamconstellations, the numbers of propositions coded into a given category were analyzed for multi- and mono-professional teams as well as for $\mathrm{t} 1$ and $\mathrm{t} 2$ separately. For that purpose, only differences in the relative numbers of propositions coded into a given category greater than $2 \%$ were considered. This limit was chosen based on the distribution of the results and the spacing between the numbers of codings. Furthermore, student's $t$-tests were performed to test for statistical significance of the differences.

Considering the belief change from $t 1$ to $t 2$ of participants in multi-professional teams only, there are differences of more than $2 \%$ of the codings in 8 categories, including categories from dimension 6 PREREQUISITES AND BARRIERS and 7 DISADVANTAGES AND CONSEQUENCES; only one difference (category 3.3 of the dimension 3 SCHOOL-LIFE AND TEACHING) is significant (Table 3A).

When looking at the belief change of participants in monoprofessional teams, however, there are 10 categories that show a difference of more than 2\%, 6 of these differences are significant (Table 3B). 


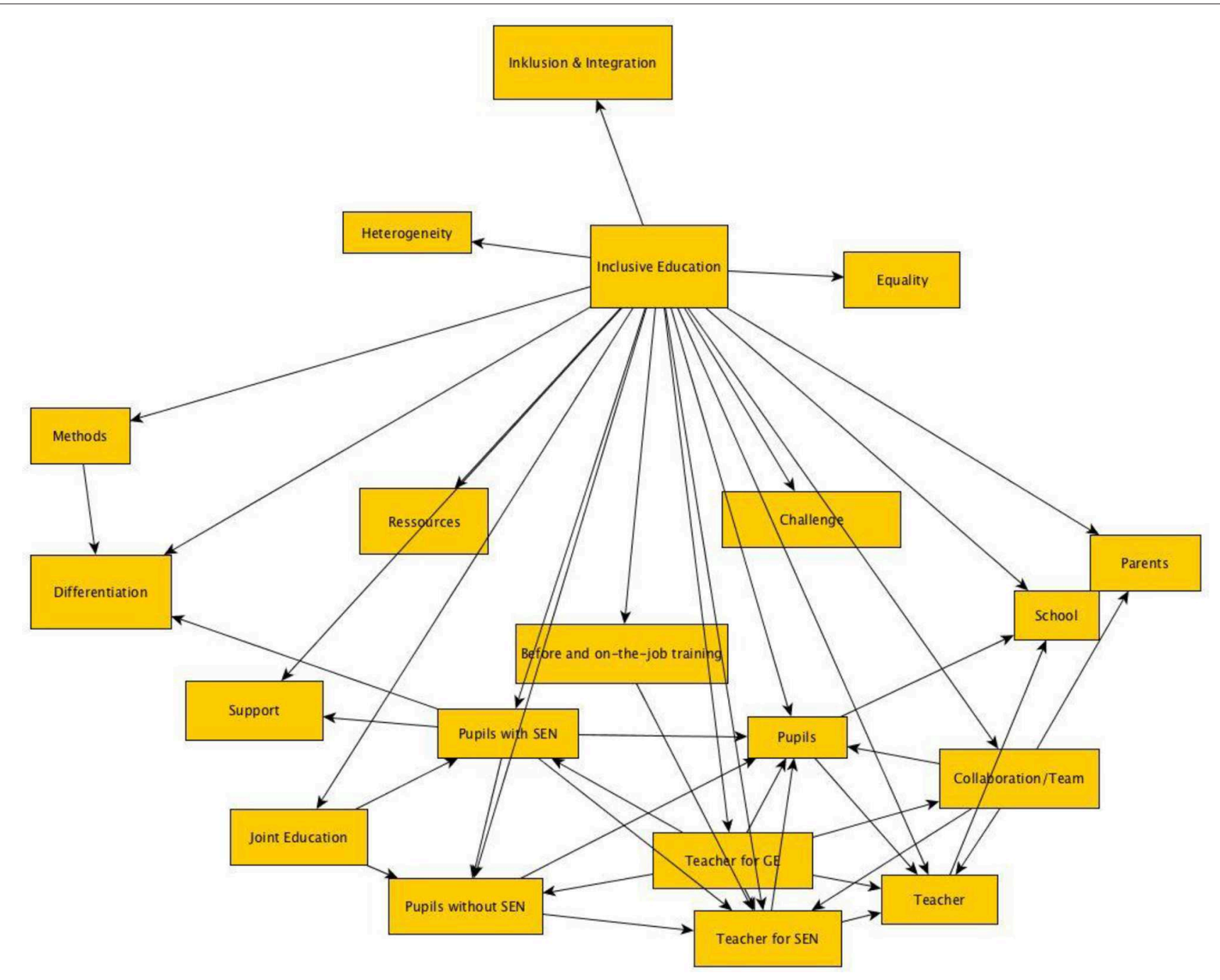

FIGURE 3 | Pathfinder network of participants in multi-professional teams at t2 $(N=63)$.

It is interesting to note that, for the members in monoprofessional teams, the number of codings into categories of dimension 1 VALUES AND ATTITUDES decreased significantly, while the number of codings into categories of dimensions 6 PREREQUisites AND BARRIERs and 7 Disadvantages AND CONSEQUENCES increased significantly. Among the 10 categories with the most codings for multi-professional teammembers are the categories 3.4 Inclusive education denotes good teaching, successful individualization and adapted differentiation (e.g., through materials, methods, concepts, co-teaching), 2.4 Inclusive education is beneficial for all pupils (e.g., with and without need for support, high and low performing pupils, etc.), and 1.4 Inclusive education needs and promotes positive attitudes, willingness, commitment, and motivation of all actors involved (e.g., teachers, parents). Categories 2.4 and 1.4 are not among the 10 most frequently coded ones for the propositions of participants in mono-professional teams. Although the shares of codings in dimensions 3 SCHOOL-LIFE
AND TEACHING and dimension 4 COLLABORATION AND PROFESSIONAL ROLES are comparable between participants in mono-professional and those in multi-professional teams, there are about twice as many codings in the dimensions 6 PREREQUISITES AND BARRIERS and 7 DISADVANTAGES AND CONSEQUENCES for the propositions of participants in monoprofessional compared to multi-professional teams. Also, the share of propositions coded into dimensions 1 VALUES AND ATTITUDES and 2 HETEROGENEITY is higher in concept maps from participants in multi-professional compared to those in mono-professional teams.

There are differences, albeit not significant, in the number of codings between participants in multi- and those in monoprofessional teams at $\mathrm{t} 1$ (Table 4A) and also at $\mathrm{t} 2$ (Table 4B).

The most frequently coded category at $t 1$ is the one addressing the need for collaboration of those involved in inclusive education (4.1) for both members in mono- and those in multi-professional teams. However, there is a comparably 


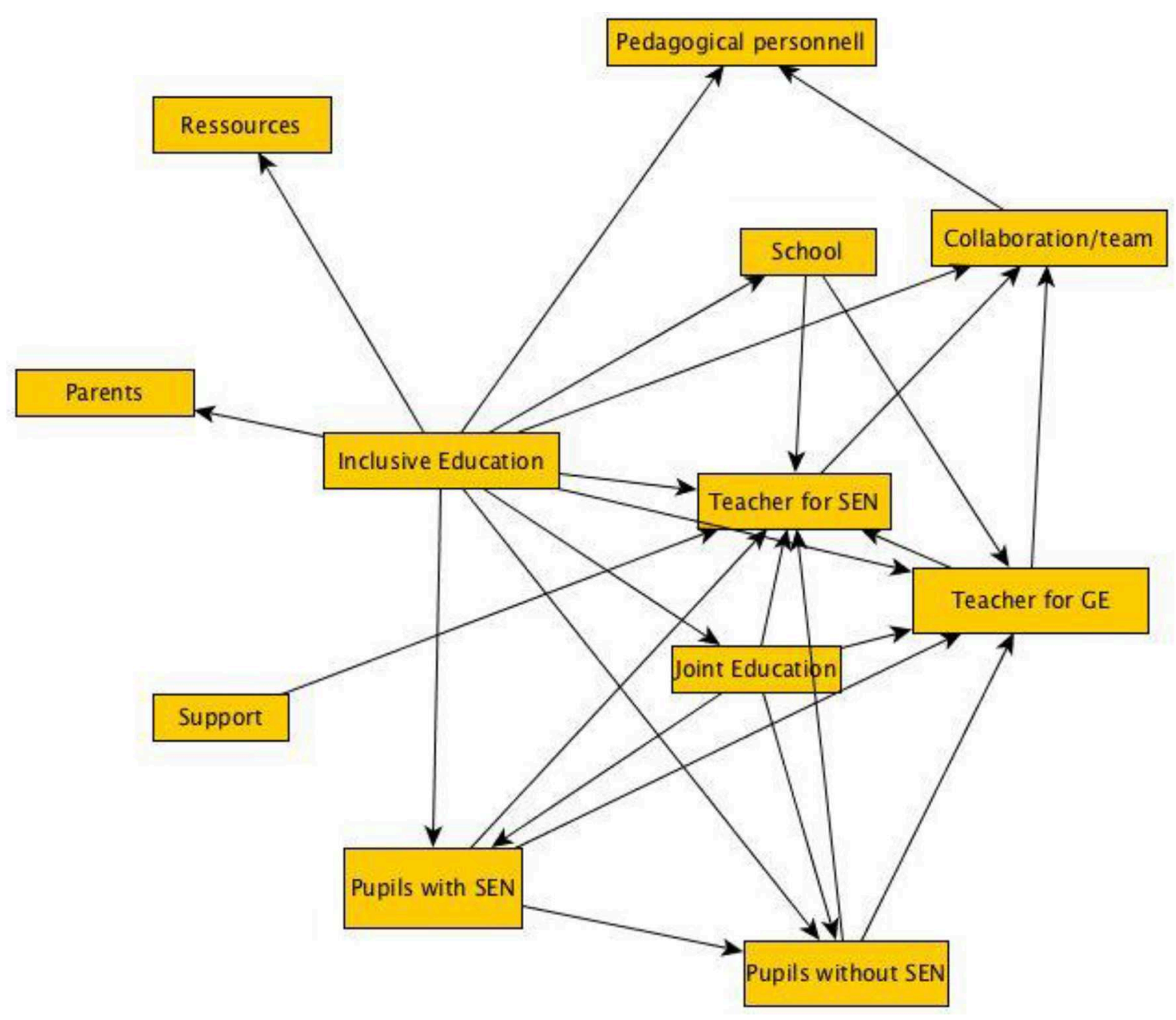

FIGURE 4 | Pathfinder network of participants in mono-professional teams at t2 $(N=34)$.

big difference between the codings of mono- and multiprofessional team-members into the category addressing equal rights and equal opportunity (1.1), where the members in monoprofessional teams have the higher share.

Looking at the codings of the propositions at $t 2$, it is interesting to note that more propositions of members in multi-professional teams are coded into the categories around schooling and teaching than of members in mono-professional teams. Furthermore, members in mono-professional teams provide about twice as many propositions coded into the dimensions denoting disadvantages and barriers of inclusion compared to members in multi-professional teams.

\section{DISCUSSION}

\section{Beliefs About Inclusive Education}

The aim of the present study is to investigate what teacher trainees' beliefs about inclusive education are and whether multiand mono-professional co-teaching in inclusive classes leads to a different change of these beliefs.

\section{Pre-service Teachers' Beliefs Before and After the Seminar}

When looking at the pathfinder network of all participants before the seminar, it becomes obvious that the concepts addressing teachers, pupils, and school in general are interconnected, meaning that all the concepts are interlinked. In contrast, concepts addressing requirements or effects of inclusive education are depicted in a spoke-structure, with Inclusive Education being the 'wheel hub' and the connected requirements and effects are the spokes, meaning that requirements and effects have only a single connection to Inclusive Education. This wheel is 'detached' from the net-structure school. This means that teacher trainees' knowledge/beliefs about school in general is a network of all relevant concepts, while the beliefs about inclusive education are not as elaborate (Kinchin et al., 2000). While teacher trainees are aware that Expert Knowledge, Resources, or Individualization are sections of the concept Inclusive Education, they stand disconnected from the sections that represent the concept school. There seem to be two compartments in the participants' belief system: one concerning school and one 
TABLE 1 | Excerpt of final system of categories (for complete system see Ritter et al., 2019).

\begin{tabular}{|c|c|}
\hline Number & Dimensions and categories \\
\hline \multicolumn{2}{|c|}{ Dimension 1: Values and attitudes } \\
\hline 1.1 & Inclusive education means equal rights, equal treatment, and equal opportunities for everyone \\
\hline 1.3 & $\begin{array}{l}\text { Inclusive education needs and promotes acceptance, tolerance, consideration, esteem as well as social } \\
\text { skills and moral values }\end{array}$ \\
\hline 1.4 & $\begin{array}{l}\text { Inclusive education needs and promotes positive attitudes, willingness, commitment, and motivation of } \\
\text { all actors involved (e.g., teachers, parents) }\end{array}$ \\
\hline \multicolumn{2}{|c|}{ Dimension 2: Heterogeneity } \\
\hline 2.4 & $\begin{array}{l}\text { Inclusive education is beneficial for all pupils (e.g., with and without need for support, high and low } \\
\text { performing pupils, etc.) }\end{array}$ \\
\hline \multicolumn{2}{|c|}{ Dimension 3: School-life and teaching } \\
\hline 3.1 & Inclusive education affects all actors involved (e.g., pupils, teachers, parents) \\
\hline 3.2 & Inclusive education takes place in the common school life and/or in the whole school context \\
\hline 3.3 & $\begin{array}{l}\text { Inclusive education means joint teaching and/or that all pupils benefit from each other, help each other } \\
\text { and support each other }\end{array}$ \\
\hline 3.4 & $\begin{array}{l}\text { Inclusive education denotes good teaching, successful individualization and adapted differentiation (e.g., } \\
\text { through materials, methods, concepts, co-teaching) }\end{array}$ \\
\hline \multicolumn{2}{|c|}{ Dimension 4: Collaboration and professional roles } \\
\hline 4.1 & $\begin{array}{l}\text { Inclusive education requires the collaboration and cooperation of all actors involved (e.g., teachers, } \\
\text { parents, pupils) }\end{array}$ \\
\hline 4.2 & $\begin{array}{l}\text { Inclusive education means that all teachers have the same accountability and responsibilities for all } \\
\text { pupils (e.g., teaching, caring, differentiating, supporting) }\end{array}$ \\
\hline 4.4 & $\begin{array}{l}\text { Inclusive education means that the special needs teacher diagnoses, teaches, supports, and fosters } \\
\text { pupils with special educational needs }\end{array}$ \\
\hline \multicolumn{2}{|c|}{ Dimension 5: Institutions and requirements } \\
\hline \multicolumn{2}{|c|}{ Dimension 6: Prerequisites and barriers } \\
\hline 6.1 & Inclusive education needs resources in general (e.g., time, money, ...) \\
\hline 6.4 & Inclusive education well-trained and qualified teachers with different expertise (e.g., methods) \\
\hline \multicolumn{2}{|c|}{ Dimension 7: Disadvantages and consequences } \\
\hline 7.1 & Inclusive education is only in its infancy, causing problems and difficulties \\
\hline 7.2 & $\begin{array}{l}\text { Inclusive education is contradictory, fails and can have negative consequences (e.g., for pupils with a } \\
\text { special need) }\end{array}$ \\
\hline 7.3 & Inclusive education is not properly implemented and/or rejected by teachers \\
\hline
\end{tabular}

As this is an excerpt, only categories that are relevant for this study are listed.

concerning requirements and effects of inclusive education. However, the concept Inclusive Education itself is the most central one connected with almost every other concept in the network. This is not particularly surprising as the guiding question for the creation of the concept maps was What is inclusive education?

The results of the qualitative analysis of the propositions also reveal that teacher trainees' beliefs about inclusive education is mainly composed of aspects regarding teaching adapted to the needs of pupils as well as the roles of teachers. In addition to that, there are aspects regarding equal rights and tolerance as well as the necessity of external resources and well-trained teachers.

This stands in contrast to Przibilla's, Linderkamp and Krämer (2018) findings according to which the majority of utterances of in-service teachers was coded into the category addressing integration, participation, and belonging (rank 1). Additionally, the category addressing community of all people in the social area of life received the third most codings. This means that in-service teachers' subjective conceptualization of inclusive education represents Göransson and Nilholm's (2014) definitiontype 4 , the community definition, which expects educational inclusion to create social communities and companionships, whereas teacher trainees' subjective conceptualization represents type 2, the specified individualized definition, which identifies inclusion as meeting the social and academic needs of pupils with disabilities. One explanation of that may be that preservice teachers' primary concern is to meet the needs of pupils with disabilities by differentiating and individualizing their teaching, whereas in-service teachers are more experienced in doing that. Their focus lays on ensuring participation of all pupils and enhancing feelings of community. This can be supported by the study of Hopkins et al. (2018), who state that teacher professionality is a composition of knowledge about self, action, and understanding of one's role in work and society. Experienced teachers see and understand their role such that they have to contribute to a functioning society. 
TABLE 2 | Ten most frequent categories for $\mathrm{t} 1$ and $\mathrm{t} 2$ (all participants and, in t2, divided into multi- and mono-professional teams).

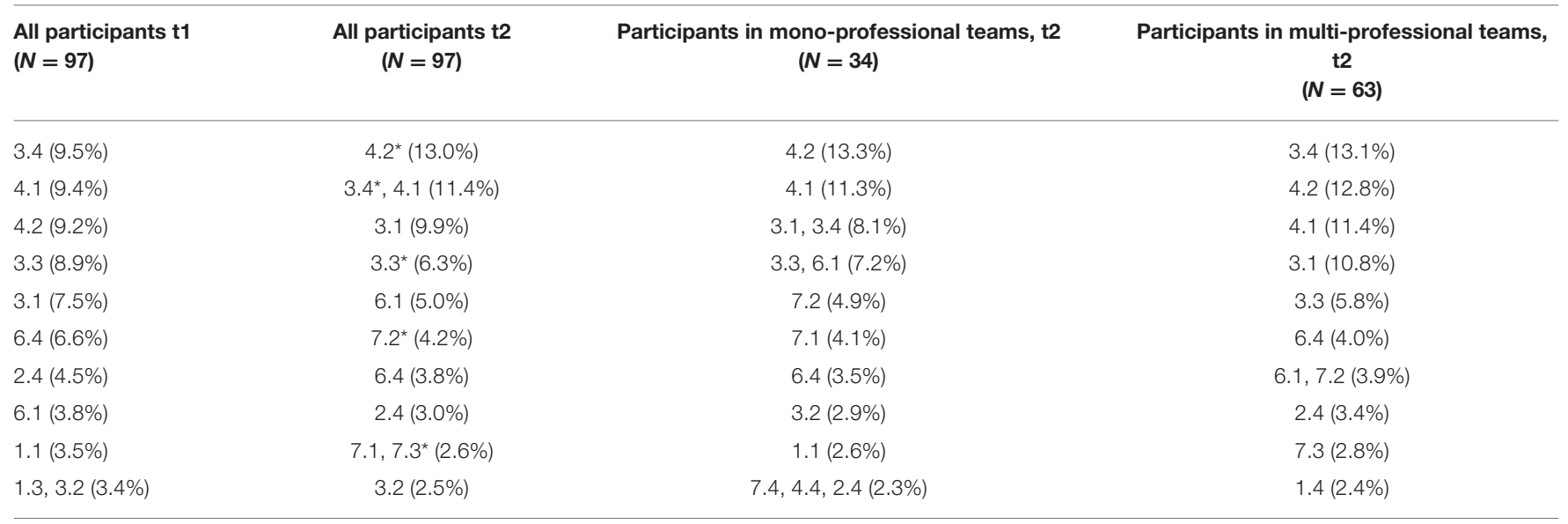

Categories are shown according to their relative number of codings (\% of total codings). Significant differences are marked with ${ }^{*} .{ }^{*} p<0.05,{ }^{* \star} p<0.01,{ }^{* \star *} p<0.001$.

TABLE 3A | Teacher trainees in multi-professional teams at $\mathrm{t} 1$ compared to t2: relative frequency of propositions coded into the respective categories.

\begin{tabular}{|c|c|c|c|c|}
\hline \multirow[t]{2}{*}{ Category } & \multicolumn{2}{|c|}{$\begin{array}{c}\text { Percentage of } \\
\text { propositions coded into } \\
\text { category }\end{array}$} & \multirow[t]{2}{*}{$\begin{array}{c}\text { Difference in } \\
\%\end{array}$} & \multirow[t]{2}{*}{$p$} \\
\hline & t1 & $\mathrm{t} 2$ & & \\
\hline 2.4 & 5.5 & 3.4 & 2.0 & 0.075 \\
\hline 3.1 & 7.4 & 10.8 & 3.4 & 0.126 \\
\hline 3.3 & 8.5 & 5.8 & 2.7 & $0.027^{\star}$ \\
\hline 3.4 & 10.1 & 13.1 & 2.9 & 0.178 \\
\hline 4.2 & 9.2 & 12.8 & 3.6 & 0.085 \\
\hline 6.2 & 9.1 & 2.2 & 2.1 & 0.063 \\
\hline 6.4 & 6.5 & 4.0 & 2.5 & 0.229 \\
\hline 7.2 & 1.7 & 3.9 & 2.2 & 0.147 \\
\hline
\end{tabular}

The pathfinder network for testing time $\mathrm{t} 2$, again, shows the net-structure with concepts addressing school in general and the spoke-structure containing requirements and effects; however, the concept differentiation is now part of the netstructure, connected with Teachers for SEN and Teachers for GE as well as Pupils with SEN and Joint education. Furthermore, it is connected with an additional concept, namely Methods. This finding allows for the assumption that participants' conception of inclusive education expanded to include aspects of joint as well as individualized teaching by both the teacher for SEN and that for GE. It is both teachers' responsibility to deliver teaching adapted to the needs of pupils with SEN.

Moreover, the pathfinder network shows a denser interconnectedness of the concepts; particularly the concepts Differentiation and Support, concepts that show a single connection in the pathfinder map of testing time $t 1$, are much more interconnected with concepts concerning schooling and teaching. This means these concepts have become part of the net-structure and are therefore part
TABLE 3B | Teacher trainees in mono-professional teams at $\mathrm{t} 1$ compared to $\mathrm{t} 2$ : relative frequency of propositions coded into the respective categories.

\begin{tabular}{lcccc}
\hline Category & \multicolumn{2}{c}{$\begin{array}{c}\text { Percentage of } \\
\text { propositions coded into } \\
\text { category }\end{array}$} & $\begin{array}{c}\text { Difference in } \\
\%\end{array}$ & $p$ \\
\cline { 2 - 3 } & $\mathbf{t 1}$ & $\mathbf{t 2}$ & & \\
\hline 1.1 & 6.2 & 2.6 & 3.6 & 0.638 \\
1.3 & 4.3 & 1.2 & 3.2 & $0.031^{\star}$ \\
2.3 & 2.2 & 0.00 & 2.2 & $0.032^{*}$ \\
4.1 & 6.5 & 11.3 & 4.8 & $0.008^{\star \star}$ \\
4.2 & 9.2 & 13.3 & 4.1 & 0.212 \\
4.3 & 4.8 & 1.2 & 3.7 & $0.039^{*}$ \\
6.1 & 5.1 & 7.2 & 2.1 & 0.354 \\
6.4 & 6.7 & 3.5 & 3.3 & $0.033^{\star}$ \\
7.1 & 1.6 & 4.1 & 2.4 & 0.304 \\
7.2 & 1.4 & 4.9 & 3.6 & $0.046^{*}$ \\
& & & &
\end{tabular}

Only categories with differences $>2$ percent are shown $\left({ }^{*} p<0.05,{ }^{* *} p<0.01\right.$, $\left.{ }^{\star * *} p<0.001\right)$.

of a network-knowledge. The practical experience of teaching in inclusive classes seems to change pre-service teachers' awareness to conceive of differentiation and individual support as being an inherent part of teaching and schooling.

The qualitative analysis of the propositions supports the structural analysis: Pre-service teachers' beliefs about inclusive education are mainly composed of aspects around school and teaching as well as aspects addressing problems and barriers; aspects concerning things like equality, participation and the like only make for a very small proportion in the composition.

This is in line with the findings of Hopkins et al. (2018), who came to discover that teacher trainees, who participated in a field-work program, developed effective strategies for differentiating tasks and promoting motivation and task 
TABLE 4A | Teacher trainees in multi- compared to mono-professional teams at t1: relative frequency of propositions coded into the respective categories.

\begin{tabular}{lcccc}
\hline Category & $\begin{array}{c}\text { Percentage of } \\
\text { propositions coded into } \\
\text { category }\end{array}$ & $\begin{array}{c}\text { Difference in } \\
\%\end{array}$ & $\boldsymbol{p}$ \\
\cline { 2 - 3 } & $\begin{array}{c}\text { Multi- } \\
\text { professional }\end{array}$ & $\begin{array}{c}\text { Mono- } \\
\text { professional }\end{array}$ & & \\
\hline 1.1 & 2.0 & 6.2 & 4.2 & 0.976 \\
2.4 & 5.5 & 2.7 & 2.8 & 0.059 \\
4.1 & 11.0 & 6.5 & 4.6 & 0.095 \\
4.3 & 1.5 & 4.9 & 3.3 & 0.155 \\
6.1 & 3.0 & 5.1 & 2.1 & 0.481 \\
\hline
\end{tabular}

Only categories with differences $>2$ percent are shown $\left({ }^{*} p<0.05\right.$, ${ }^{* *} p<0.01$, $\left.{ }^{\star \star *} p<0.001\right)$.

TABLE 4B | Teacher trainees in multi- compared to mono-professional teams at t2: relative frequency of propositions coded into the respective categories.

\begin{tabular}{lcccc}
\hline Category & $\begin{array}{c}\text { Percentage of } \\
\text { propositions coded into } \\
\text { category }\end{array}$ & $\begin{array}{c}\text { Difference in } \\
\%\end{array}$ & $p$ \\
\cline { 2 - 3 } & $\begin{array}{c}\text { Multi- } \\
\text { professional }\end{array}$ & $\begin{array}{c}\text { Mono- } \\
\text { professional }\end{array}$ & & \\
\hline 3.1 & 10.9 & 8.1 & 2.8 & 0.263 \\
3.4 & 13.1 & 8.1 & 5.0 & 0.071 \\
6.1 & 3.9 & 7.2 & 3.4 & 0.114 \\
7.1 & 1.9 & 4.1 & 2.1 & 0.399 \\
\hline
\end{tabular}

Only categories with differences $>2$ percent are shown $\left({ }^{*} p<0.05,{ }^{* *} p<0.01\right.$, $\left.{ }^{\star \star *} p<0.001\right)$.

engagement. Differentiation strategies are not only essential for teaching in inclusive classrooms, but also contribute to an increased self-efficacy expectation of teacher (trainee)s, as the experience to be able to motivate students and provide alternative explanations when students are confused are important contexts for its development (Tschannen-Moran and Hoy, 2007). Just as well, Jordan et al. (2009) concluded from their literature review that initial teachers' beliefs are malleable through teachers' direct experience with children in their classrooms, where pre-service teachers acquire evidence of improvement in student learning. This conclusion seems to be confirmed with the data of the present study.

However, the practical experience also leads to the recognition of barriers and possible disadvantages of inclusive education. This is in contrast to the findings of Gökdere (2012), Boyle et al. (2013), and Specht et al. (2015), who state that new teachers seem to be more positive toward inclusive education than those with years of experience. They also found out that direct experience in teaching students with special needs increases selfefficacy expectations, particularly experience that is of longer duration. For the participants in this study, the opposite seems to be the case, and the reason for this may either be the poor implementation of inclusive education in some German schools (cf. VBE, 2017) or inadequate instruction during the practical experience (cf. Peebles and Mendaglio, 2014).

\section{Multi- and Mono-professional Teams: Comparison of Beliefs}

A comparison of the pathfinder networks of participants in multi-professional teams with that of participants in monoprofessional teams at $\mathrm{t} 2$ reveals that the latter is much less elaborate, lacking concepts like heterogeneity, equality, differentiation, and methods, which are constituents of the subjective theories of participants in multi-professional teams. The subjective belief about inclusive education of teacher trainees in mono-professional teams only includes concepts addressing school in general, all the related actors, and - additionally the concepts collaboration/team and resources. In other words, beliefs of teacher trainees in mono-professional teams do not expand to include concepts that should actually constitute inclusive education: equality, heterogeneity, and differentiation, as is the case for participants in multi-professional teams. Additionally, the concept Methods, Legal requirements, and Learning groups are included in the pathfinder network of participants in multi-professional teams at $t 2$, but not in the network of all participants at $\mathrm{t} 1$. This means that the preservice teachers working in multi-professional teams conceive of inclusive education as teaching that has to fulfil certain legal requirements, affects different learning groups, and requires different methods.

Again, this is supported by the qualitative analysis of the propositions: Teacher trainees who work in mono-professional teams conceive of inclusive education as only concerning school in general and as being problematic, whereas teacher trainees working in multi-professional teams conceive of inclusive education as also addressing equality and heterogeneity.

One explanation for that may be that there is a transfer of expertise between the two partners of different disciplines. In Scruggs's, Mastropieri and McDuffie (2007) meta analysis, teachers who were members in multi-professional teams reported to have benefitted from their partners' expertise and to have gained higher levels of self-efficacy. This is also supported by the findings of Alvarez-McHatton and Daniel (2008), which indicate that both the special education majors and the English education majors gained knowledge about the respective other's expertise by a co-teaching experience at the pre-service level. As for the results of the present study, this means that the teacher trainees in multi-professional teams made use of both partners' expertise to expand their beliefs of inclusive education to include aspects like differentiation, equality, and heterogeneity. Additionally, teacher trainees in multi-professional teams may have had more opportunities to discuss their beliefs with their partners of different disciplines while talking about each partners' expertise. Discussing beliefs entails reflecting on them; and just this has been shown by several scholars to facilitate change (Howard et al., 2000; Brownlee et al., 2001).

For the teacher trainees in mono-professional teams, there was no such "other" expertise and therefore probably little need to make explicit their implicit beliefs, reflect on them, negotiate different strategies and attempts to inclusive education. 
In other words, there was no challenging of beliefs concerning teaching strategies or learning abilities. For members in multiprofessional teams, on the other hand, these negotiations may have been reason for conflict, and by trying to resolve them, there might be restructuring of the belief system. According to Stein (2011), it is not the development of competencies that makes up professionalism for inclusive education, but it is predominantly learning on and in contradiction. The contradiction the teacher trainees encountered here may ignite the critical approach to an inclusive pedagogy and thus add to their expansion of beliefs.

\section{Limitations}

The present study is of exploratory nature, the purpose of which is to provide insight into the complex field of teacher beliefs about inclusive education and its transformation through multi- or mono-professional co-teaching. Moreover, it constitutes qualitative research that does not strive to produce generalizable results.

The authors are aware that there are several confounding factors in the research study. For one, teacher trainees were in different semesters and programs of their study, which means that the study was performed with a very heterogeneous group of pre-service teachers at very different levels of expertise.

Furthermore, the practical experience was gained in nonstandardized environments at different schools and school-types. Although the mentoring teachers at the schools were instructed regarding the pre-service teachers' tasks in class, university teachers' expectations, the scope of the research study and the like, there are still non-comparable framework conditions during the practicum.

Moreover, as the basis is an elective-compulsory seminar, participants are not neutral towards inclusive education; rather, they opted to attend this seminar because they are positive toward it. Therefore, the results are not representative of the basic population of pre-service teachers at the University of Wuppertal.

Another confounding factor may be the research methodology. Pre-service teachers were to construct concept maps, a method which may not be familiar. Therefore, preservice teachers may have been too distracted by the creation and thus may have not been able to fully visualize their subjective concept. Consequently, it is possible that the results do not represent pre-service teachers' beliefs in its entirety.

\section{Conclusion and Implementation}

Despite the above-mentioned and further limitations, the results are of value for teacher training and future research. The evaluation of the concept maps using graph-theoretical as well as content-analysis methods provides insight into pre-service teachers' concepts of inclusive education, the interconnectedness of the composing concepts, and lacks of connections between specific concepts. Thus, the results of this study may be used as a basis for the conception of seminars to prepare teachers for inclusive education.

Pre-service teachers' beliefs appear to be mainly composed of aspects concerning schooling and teaching. Furthermore, the results reveal that, through practical experience in multiprofessional co-teaching teams, teacher trainees' beliefs about inclusive education expand to include concepts denoting good inclusive education, i.e., differentiation, equality, and heterogeneity. Practical experience in mono-professional teams, however, does not lead to the expansion of beliefs; rather, beliefs are and remain confined to constituents regarding school in general as well as disadvantages and barriers of inclusive education.

The objective of this study is to explore teacher trainees' conceptualization of inclusion before and after practical experience in one of a co-teaching-constellation (multi- or mono-professional). However, the applied mixed-methodanalysis also allows for the deduction of a definition of inclusive education. On the basis of multi-professionally working teacher trainees' conceptualization, the following definition is proposed: 'Inclusive Education is the joint education of all pupils; it calls for adequate methods to facilitate differentiated instruction and support for all pupils. Additionally, it calls for the collaboration and teamwork of all teachers, parents, and all pupils to result in equality and appreciation of heterogeneity; in that, it constitutes a challenge and calls for the provision of suitable resources.' This means, the definition proposed here covers not only the academic success of pupils with SEN, but that of all the pupils in the class. In addition, it covers that the aim of inclusion be to value heterogeneity and equal opportunities, an aspect that goes beyond academic success pointing at the need for social change.

It is essential that pre-service teachers be prepared to act adequately to meet the needs of all pupils. Therefore, as beliefs are action guiding in the classrooms, it is also essential to expand those beliefs to include supportive measures. Multi-professional co-teaching during teacher training seems to be an appropriate method to meet this requirement.

\section{DATA AVAILABILITY}

The raw data supporting the conclusions of this manuscript will be made available by the authors, without undue reservation, to any qualified researcher.

\section{ETHICS STATEMENT}

This study was carried out in accordance with the ethical guidelines of the German Association for Educational Sciences. The study has not been subjected to review by an ethical committee since, according to German legislation regarding research on human subjects, research needs approval from an ethical committee only in cases where personal and sensitive information is handled, when physical interventions are made, or when the subjects may be harmed. In line with this, approval from an ethical committee is not required by the university where the research was conducted. All subjects have been informed about the purpose of the research, that their participation is voluntary, and that they can interrupt their participation at any time. Written informed consent have been 
given by all subjects. Within the study, responses were given in anonymized form, the authors did not have access to identifiable information.

\section{AUTHOR CONTRIBUTIONS}

RR conducted the research study including data collection and analysis. AW contributed significantly to designing and conducting the academic seminar and also to critical reading of the manuscript. GL was the head of the department and supervisor. PK contributed significantly to the methodologies used in the study.

\section{REFERENCES}

Alvarez-McHatton, P., and Daniel, P. (2008). Co-teaching at the pre-service level: special education majors collaborate with English education majors. Teach. Educ. Spec. Educ. 31, 118-131. doi: 10.1177/088840640803100205

Artiles, A., Kozleski, E., Dorn, S., and Christensen, C. (2006). Learning in inclusive education research: re-mediating theory and methods with a transformative agenda. Rev. Res. Educ. 30, 65-108. doi: 10.3102/0091732X030001065

Bendixen, L., and Rule, D. (2004). An integrative approach to personal epistemology: a guiding model. Educ. Psychol. 39, 69-80. doi: 10.1207/s15326985ep3901_7

Biesta, G., Priestley, M., and Robinson, S. (2015). The role of beliefs in teacher agency. Teach. Teach. Theory Pract. 21, 624-640. doi: 10.1080/13540602.2015.1044325

Bourdieu, P., and Passeron, J.-C. (1990). Reproduction in Education, Society and Culture. Thousand Oaks, CA: SAGE Publications.

Boyle, C., Topping, K., and Jindal-Snape, D. (2013). Teachers' attitudes towards inclusion in high schools. Teach. Teach. Theory Pract. 19, 527-542. doi: 10.1080/13540602.2013.827361

Brownlee, J., Purdie, N., and Boulton-Lewis, G. (2001). Changing epistemological beliefs in pre-service teacher education students. Teach. High. Educ. 6, 247-268. doi: 10.1080/13562510120045221

Farell, P. (2004). School psychologists. Making inclusion a reality for all. Sch. Psychol. Int. 25, 5-19. doi: 10.1177/0143034304041500

Gale, T., Mills, C., and Cross, R. (2017). Socially inclusive teaching: belief, design, action as pedagogic work. J. Teach. Educ. 68, 345-356. doi: $10.1177 / 0022487116685754$

Gökdere, M. (2012). A comparative study of the attitude, concern, and interaction levels of elementary school teachers and teacher candidates toward inclusive education. Educ. Sci. Theory Pract. 12, 2800-2807.

Göransson, K., and Nilholm, C. (2014). Conceptual diversities and empirical shortcommings - a critical analysis of research on inclusive education. Eur. J. Spec. Needs Educ. 29, 265-280. doi: 10.1080/08856257.2014.933545

Grosche, M. (2015). "Was ist inklusion? [What is inclusion?]," in Inklusion von Schülerinnen und Schülern mit Sonderpädagogischem Förderbedarf in Schulleistungserhebungen, eds P. Kuhl, P. Stanat, B. Lütje-Klose, C. Gresch, H. Pant, and M. Prenzel (Wiesbaden: Springer), 17-39.

Guskey, T. (2002). Professional development and teacher change. Teach. Teach. Theory Pract. 8, 381-391. doi: 10.1080/135406002100000512

Hopkins, S., Round, P., and Barley, K. (2018). Preparing beginning teachers for inclusion: designing and assessing supplementary fieldwork expiriences. Teach. Teach. Theory Pract. 24, 915-930. doi: 10.1080/13540602.2018.1495624

Howard, B., McGee, S., Schwartz, N., and Purcell, S. (2000). The experience of constructivism: transforming teacher epitemology. J. Res. Comput. Educ. 32, 455-465. doi: 10.1080/08886504.2000.10782291

Jordan, A., Schwartz, E., and McGhie-Richmond, D. (2009). Preparing teachers for inclusive classrooms. Teach. Teach. Educ. 25, 535-542. doi: 10.1016/j.tate.2009.02.010

Kagan, D. M. (1992). Professional growth among preservice and beginning teachers. Rev. Educ. Res. 62, 129-169. doi: 10.3102/00346543062002129

\section{FUNDING}

This work was supported by the Ministry of Education and Research within the framework of the Gemeinsame Qualitätsoffensive Lehrerbildung [joint quality offensive for teacher training] of the Federal Government of Germany and the Länder [grant number: 0JA1507].

\section{ACKNOWLEDGMENTS}

The authors are indebted to Anja Metscher for digitalizing all the concept maps.

Kinchin, I., Hay, D., and Adams, A. (2000). How a qualitative approach to concept map analysis can be used to aid learning by illustrating patterns of conceptual development. Educ. Res. 42, 43-57. doi: 10.1080/001318800363908

Makoelle, T. (2014). Pedagogy of inclusion. A quest for inclusive teaching and learning. Mediterr. J. Soc. Sci. 5, 1259-1267. doi: 10.5901/mjss.2014.v5n20p1259

Mandl, H., and Huber, G. (1983). Subjektive theorien von lehrern. Psychol. Erziehung Unterricht 30, 98-112.

Mayring, P. (2008). Qualitative Inhaltsanalyse: Grundlagen und Techniken [Qualitative Content Analysis: Basics and Techniques]. Weinheim: Beltz.

Mayring, P. (2015). Qualitative Inhaltsanalyse. Grundlagen und Techniken [Qualitative Content Analysis: Basics and Techniques] (12. überarbeite Auflage ed.). Weinheim: Beltz.

Mühling, A. (2014). Investigating Knowledge Structures in Computer Science Education (T. U. München, Ed.). Available online at: https://mediatum.ub.tum. de/doc/1190967/1190967.pdf (accessed February 21, 2018).

Mühling, A. (2017). Concept landscapes:aggregating concept maps for analysis. $J$. Educ. Data Mining 9, 1-30.

Nespor, J. (1987). The role of beliefs in the practice of teaching. J. Curr. Stud. 19, 317-328. doi: 10.1080/0022027870190403

Nilhom, C., and Göransson, K. (2017). What is meant by inclusion? An analysis of European and North American journal articles with high impact. Eur. J. Spec. Needs Educ. 32, 437-451. doi: 10.1080/08856257.2017.12 95638

Novak, J., and Cañas, A. (2010). "The universality and ubiquitousness of concept maps," in Concept Maps: Making Learning Meaningful, Vol. 1, eds J. Sanchez, A. Cañas, and J. Novak (Viña del Mar: Universidad de Chile), 1-13.

Novak, J. D., and Cañas, A. J. (2008). The Theory Underlying Concept Maps and How to Construct and Use them. Technical Report IHMC Cmap Tools. Available online at: http://cmap.ihmc.us/docs/theory-of-concept-maps (accessed Fbruary 21).

Peebles, J., and Mendaglio, S. (2014). The impact of direct experience on preservice teachers self-efficacy for teaching in inclusive classrooms. Int. J. Inclus. Educ. 18, 1321-1336. doi: 10.1080/13603116.2014.899635

Przibilla, B., Linderkamp, F., and Krämer, P. (2018). Subjektive definition von lehrkräften $\mathrm{zu}$ inklusion - eine explorative studie [Subjective theories of inclusive education - an exploratory study]. Empirische Sonderpädagogik $3,232-247$.

Richardson, V. (1996). "The role of attitudes and beliefs in learning to teach," in Handbook of Research on Teacher Education, ed J. Sikula (New York, NY: Macmillan), 102-119.

Richarson, V., and Placier, P. (2002). “Teacher change," in Handbook of Reaserch of Teaching, eds V. Richardson (Washington, DC: AERA), 905-947.

Ritter, R., Wehner, A., Lohaus, G., and Krämer, P. (2018). Multi-professional and mono-professional collaboration and its association with both student teacher attitude towards, and concepts of, inclusive education. Emp. Spec. Educ. Int. 1, 185-203.

Ritter, R., Wehner, A., Lohaus, G., and Krämer, P. (2019). "Konzepte von schulischer Inklusion bei Lehramtsstudierenden: entwicklung eines Kategorienschemas durch induktive, zusammenfassende qualitative Inhaltsanalyse [Concepts of inclusion of teacher traines: development of 
a system of categories through inductive, summarizing qualitative content analysis]," in Lehren und Lernen im Spannungsfeld von Normalität und Diversität, eds E. von Stechow, K. Müller, M. Esefeld, B. Klocke, and P. Hachstein (Bad Heilbrunn: Julius Klinkhardt), 83-94.

Scruggs, T. E., Mastropieri, M. A., and McDuffie, K. A. (2007). Co-teaching in inclusive classrooms: a metasynthesis of qualitative research. Except. Child. 73, 392-416. doi: 10.1177/001440290707300401

Silverman, J. (2007). Epistemological beliefs and attitudes toward inclusion of pre-service teachers. Teach. Educ. Spec. Educ. 30, 42-51. doi: $10.1177 / 088840640703000105$

Specht, J., McGhie-Richmond, D., Loreman, T., Mirenda, P., Bennett, S., Gallagher, T., et al. (2015). Teaching in inclusive classrooms: efficacy and beliefs of Canadian preservice teachers. Int. J. Inclus. Educ. 20, 1-15. doi: $10.1080 / 13603116.2015 .1059501$

Stein, A.-D. (2011). "Inklusion in der Hochschuldidaktik - Oder die Frage: wie können Studierende daruf vorbereitet warden," in Einer Ausgrenzenden Gesellschaft Inklusive Strukturen zu Etablieren? [Inclusion in High-school didactics - or the question how students can be prepared to establish inclusive structures in an exclusive society] Broschüre der Gewerkschaft Erziehung und Wissenschaft. Frankfurt.

Tschannen-Moran, M., and Hoy, A. (2007). The differential antecedants of selfefficacy beliefs of novice and experienced teachers. Teach. Teach. Educ. 23, 944-956. doi: 10.1016/j.tate.2006.05.003
United Nations (2006). Convention on the Rights of Persons With Disablities. Available online at: https://www.un.org/development/desa/disabilities/ convention-on-the-rights-of-persons- with-disabilities/article-24-education. html (united nations convention on the rights of disabled persons 2006) (accessed September, 2018).

VBE (2017). Inklusion an Schulen aus Sicht der Lehrkräfte in Deutschland Meinungen, Einstellungen und Erfahrungen [Inclusion at Schools From the Perspective of Teachers in Germany - Opinions, Attitudes and Experience]. Available online at: https://www.vbe.de/fileadmin/user_upload/VBE/Service/ Meinungsumfragen/2017_05_10_Inklusion_an_Schulen_Auswertung.pdf (accessed September 04, 2018).

Conflict of Interest Statement: The authors declare that the research was conducted in the absence of any commercial or financial relationships that could be construed as a potential conflict of interest.

Copyright $\odot 2019$ Ritter, Wehner, Lohaus and Krämer. This is an open-access article distributed under the terms of the Creative Commons Attribution License (CC BY). The use, distribution or reproduction in other forums is permitted, provided the original author(s) and the copyright owner(s) are credited and that the original publication in this journal is cited, in accordance with accepted academic practice. No use, distribution or reproduction is permitted which does not comply with these terms. 